\title{
EXPERIMENTAL VERIFICATION OF POLYMERIC DISTILLATION UNIT
}

\author{
T. Kroulíková*, T. Brožová ${ }^{* *}$, E. Bartuli***, M. Raudenský ${ }^{* * * *}$
}

\begin{abstract}
Desalination is common solution to a fresh water scarcity. The common desalination units are made of metal, which bring some disadvantage as corrosion or heavy weight. The presented paper discribe principle of polymeric distillation and present results of experimental verification of prototype of fully polymeric distillation. This prototype is based on air gap membrane distillation and combines two type of polymeric hollow fibers. Porous hollow fibers were used as membrane and the non-porous hollow fibers were used for the condenser. The prototype was operated in long-term continuous operation. Six experiments with different flow rate and temperature were done. During testing the temperature, humidity and amount of condensate was measured.
\end{abstract}

Keywords: Polymeric hollow fiber, Membrane hollow fiber, Distillation, Desalination.

\section{Introduction}

Desalination of sea or brackish water is nowadays common solution to fresh water scarcity. In some parts of the world it is the only way how to get drinking water. The desalination units used are usually made of metal, which brings some disadvantages. The long term exposure of the salt water leads to extensive corrosion, and in addition to this the desalination units are heavy and expensive. The attempts to make them from polymers, appeared, for example (Song, 2018) studied polymer hollow fiber heat exchanger in application to desalination.

In this paper the fully polymeric distillation unit is presented. This unit combines two types of polymer hollow fibers. First of them are membrane hollow fibers which allows transfer only gas phase. This is because of combination of hydrophobic surface of membrane and size of pores. Membrane hollow fibers can be also used for air filtration (Bulejko 2018) or for ammonia recovery (Darestani 2017). The second type are thermal hollow fibers which provides heat transfer, specifically condensation of vapour. The thermal conductivity of polymers is low, but this can be overcome by using the hollow fibers with wall thickness less than $100 \mu \mathrm{m}$ (Chen, 2016). In addition to corrosion resistance, polymer hollow fiber exchangers provides easy shaping and machining. They are low weight and their cost is lower than the metal unit. They are also environmental friendly, since the energy required to produce a unit of mass of plastic is about 2 times less than a unit of metal (Zarkadas, 2004).

The principle behind polymeric distillation is air gap membrane distillation. Membrane distillation is thermally driven separation process. Its driving force is the vapour pressure difference induced by the temperature differences between the two sides of the membrane pores. This temperature difference is in the order of $5-20^{\circ} \mathrm{C}$ (Sørensen, 2014). There are several types of membrane distillation - direct contact, air gap, sweep gas, vacuum etc. As name of air gap membrane distillation suggest there is space filled with air (air gap) between the membrane and condensation surface (Drioli, 2015).

* Ing. Tereza Kroulíková: Laboratory of Heat Transfer and Fluid Flow, Faculty of Mechanical Engineering, Brno University of Technology, Technická 2896/2; 619 09, Brno; CZ, Tereza.Kroulikova@ vut.cz

** Ing. Tereza Brožová, PhD.: Laboratory of Heat Transfer and Fluid Flow, Faculty of Mechanical Engineering, Brno University of Technology, Technická 2896/2; 619 09, Brno; CZ, Tereza.Brozova@ vut.cz

*** Ing. Erik Bartuli: Laboratory of Heat Transfer and Fluid Flow, Faculty of Mechanical Engineering, Brno University of Technology, Technická 2896/2; 619 09, Brno; CZ, Erik.Bartuli1 @ vut.cz

***** Prof. Ing. Miroslav Raudenský, CSc.: Laboratory of Heat Transfer and Fluid Flow, Faculty of Mechanical Engineering, Brno University of Technology, Technická 2896/2; 619 09, Brno; CZ, raudensky@ fme.vutbr.cz 


\section{Principle of polymeric distillation}

As was mentioned, the main idea of polymeric distillation is to combine membrane and thermal hollow fibers. The hot brine flows inside the membrane hollow fiber and evaporates there. Since the membrane hollow fibers are made from hydrophobic polypropylene and are porous, they allow to pass through only the gas phase. The membrane module is placed inside distillation tunnel, where ambient temperature is significantly lower than inside the fiber, therefore the evaporated water passes through membrane into the tunnel. There is an electrical fan inside the tunnel, which forces the air to circulate inside the tunnel. Next to the membrane module in the direction of air flow stands cooler. The cooler is composed of polymer hollow fiber heat exchanger and the evaporated water condensate on it and the condensate is collected.

The membrane module of presented prototype consists of four bundles of polypropylene hollow fibers produced by ZENA s.r.o. Ostopovice, Czechia, see Fig. 1a. The membrane hollow fibers have outside diameter $0.5 \mathrm{~mm}$ with the average pore size $0.1 \mu \mathrm{m}$ and the total inside surface area is $1.5 \mathrm{~m}^{2}$. Around $50 \%$ of hollow fiber surface consists of pores. The thermal module is made of non-porous polymer hollow fibers. The heat exchanger with chaotic structure was used, see Fig. $1 \mathrm{~b}$. The fibers have $0.8 \mathrm{~mm}$ outside diameter and their outside surface area is equal to $0.3 \mathrm{~m}^{2}$. Both modules are placed inside the rectangular tunnel, see Fig. 2.

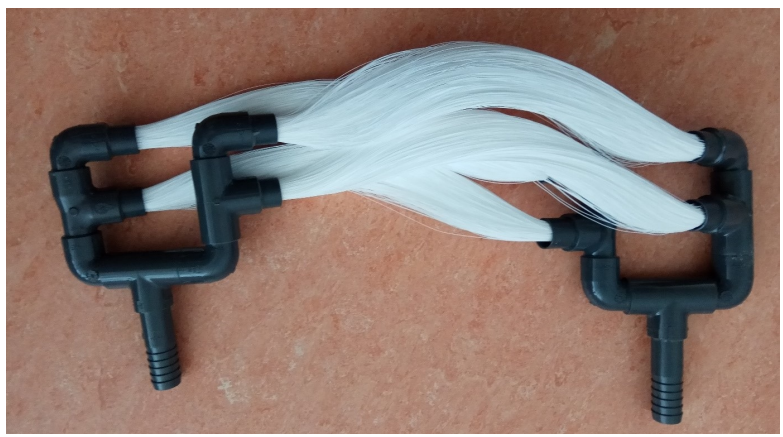

(a) Membrane module

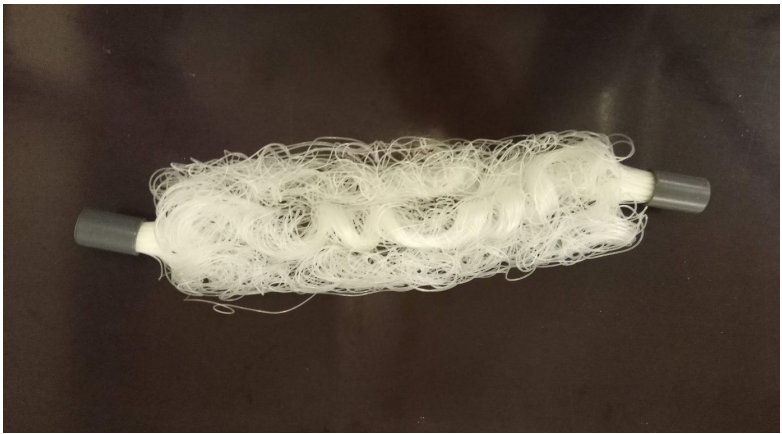

(b) Thermal module

Fig. 1: Hollow fibre modules

\section{Experimental verification}

The functionality of the prototype was verified during continuous long-term operation. During this time six experiments were done. The brine was heated up in a tub. It was pumped inside the membrane module and back to the tub. Tapped water from water supply system severed as coolant. All experiments (EXP01EXP06) were done in steady-state according to plan presented in Table 1.

Tab. 1: Measurement plan

\begin{tabular}{|c|c|c|c|c|}
\hline & $T_{m, i n}\left[{ }^{\circ} C\right]$ & $\begin{array}{l}\text { Flow rate inside membrane } \\
\text { module }[l / h]\end{array}$ & $\begin{array}{l}\text { Flow rate inside thermal } \\
\text { module }[l / \mathrm{min}]\end{array}$ & Air speed $[\mathrm{m} / \mathrm{s}]$ \\
\hline EXPO1 & 55 & 100 & 360 & 1.5 \\
\hline ЕХРО2 & 55 & 60 & 360 & 1.5 \\
\hline EXP03 & 60 & 100 & 360 & 1.5 \\
\hline ЕХР04 & 60 & 60 & 360 & 1.5 \\
\hline EXP05 & 65 & 100 & 360 & 1.5 \\
\hline EXP06 & 65 & 60 & 360 & 1.5 \\
\hline
\end{tabular}


The measurement was done at three different inlet temperatures of membrane module: $55^{\circ} \mathrm{C}, 60^{\circ} \mathrm{C}$ and $65^{\circ} \mathrm{C}$. The flow of hot brine alternated in 60 and $100 \mathrm{l} / \mathrm{h}$. The velocity of the air inside the tunnel remained the same for the whole operation time.

Temperature inside the tunnel $\left(T_{1}-T_{4}\right)$ was measured by four thermal sensors Pt100, which were placed in front of the membrane module (Pt100-A), between the membrane and thermal module (Pt100-B), behind the thermal module (Pt100-C) and in the other side of the rectangular tunnel (Pt100-D). Another four sensors (Pt100-E - Pt100-H) of the same type measured temperature of brine at inlet of membrane module $\left(T_{m, i n}\right)$, temperature of brine at outlet of membrane module $\left(T_{m, o u t}\right)$, temperature of coolant at inlet and outlet of thermal module ( $T_{t, \text { in }}$ and $\left.T_{t, \text { out }}\right)$ respectively. There are also four humidity sensors $\left(H_{1}-H_{4}\right)$ next to each temperature sensor inside the distillation tunnel, see Fig. 2. In addition the velocity of air was monitored.
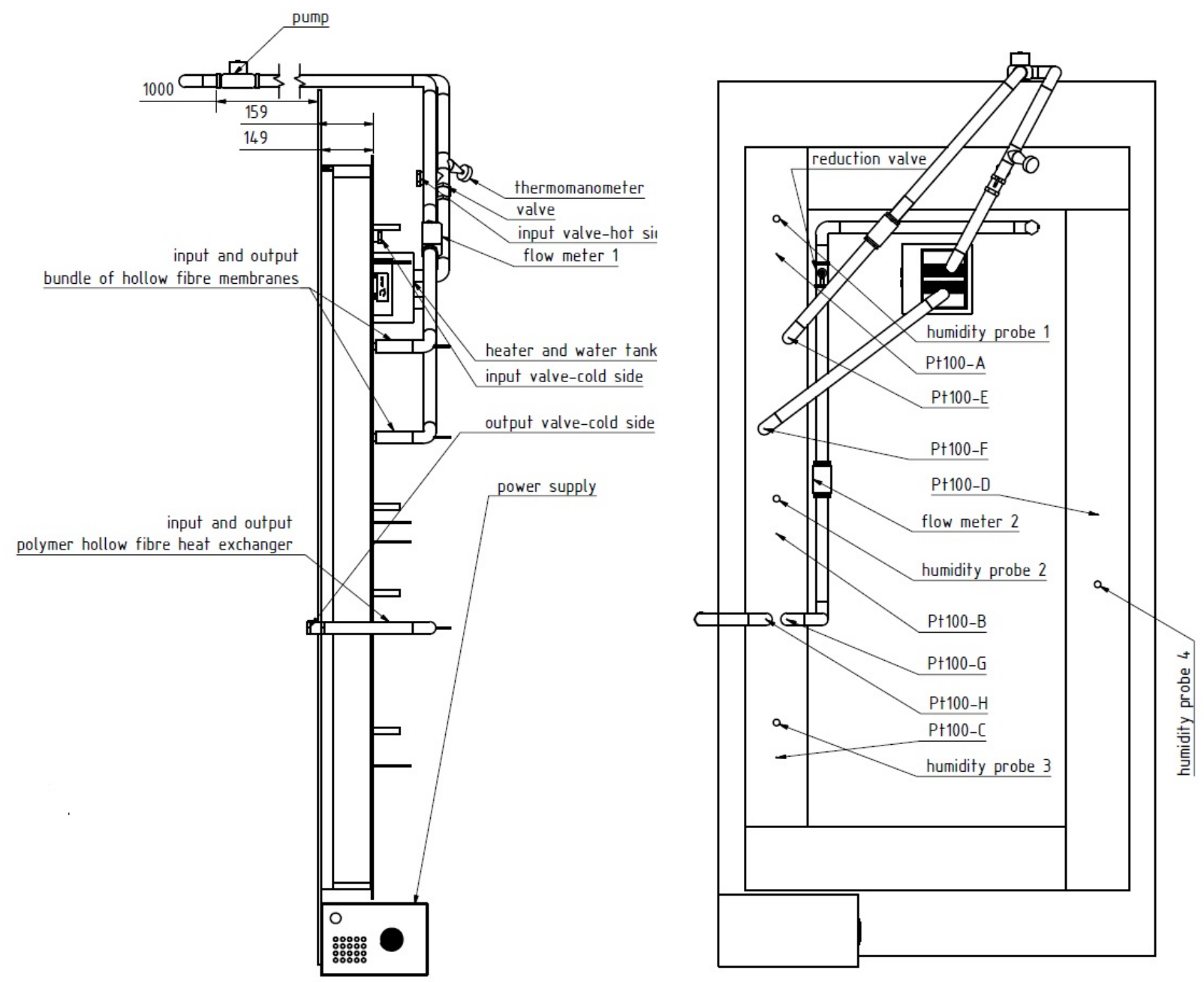

Fig. 2: Scheme of distillation tunnel, from side (left), from above (right)

The first drops of water appeared on the surface of thermal module when inlet temperature of membrane module was $30^{\circ} \mathrm{C}$. The difference between the temperature inside membrane fibers and ambient temperature was around $10^{\circ} \mathrm{C}$. This observation is in concordance with knowledge already mentioned in introduction. Table 2 presents values of measured quantities - temperature, relative humidity, amount of condensate (condensate).

The temperature and relative humidity inside tunnel changed according to the place. Naturally the highest temperature was between the membrane and thermal module $\left(T_{2}\right)$, where the hot water steam was present. Then the water steam condensed on the thermal module and the air was cooled, therefore the lowest temperature occurred behind the thermal module $\left(T_{3}\right)$, where flowed cold water. The temperature in the other side $\left(T_{4}\right)$ and in front of membrane module $\left(T_{1}\right)$ was similar and did not change rapidly. Similarly, the relative humidity reached the highest value between hollow fibers modules $\left(H_{2}\right)$ and then dropped as the 


\section{Tab. 2: Measured data}

\begin{tabular}{l|lllllllllllc} 
& $T_{m, o}$ & $T_{t, i}$ & $T_{t, o}$ & $H_{1}$ & $T_{1}$ & $H_{2}$ & $T_{2}$ & $H_{3}$ & $T_{3}$ & $H_{4}$ & $T_{4}$ & condensate \\
& {$\left[{ }^{\circ} \mathrm{C}\right]$} & {$\left[{ }^{\circ} \mathrm{C}\right]$} & {$\left[{ }^{\circ} \mathrm{C}\right]$} & {$[\%]$} & {$\left[{ }^{\circ} \mathrm{C}\right]$} & {$[\%]$} & {$\left[{ }^{\circ} \mathrm{C}\right]$} & {$[\%]$} & {$\left[{ }^{\circ} \mathrm{C}\right]$} & {$[\%]$} & {$\left[{ }^{\circ} \mathrm{C}\right]$} & {$[\mathrm{ml} / \mathrm{h}]$} \\
\hline EXP01 & 53.3 & 10.6 & 11.1 & 83.3 & 19.9 & 93.2 & 24.9 & 88 & 17.3 & 88.2 & 19 & 739 \\
EXP02 & 52.3 & 10.6 & 11.1 & 82.7 & 19.8 & 93.4 & 24.6 & 89.7 & 17.4 & 85.9 & 19 & 778 \\
EXP03 & 58.4 & 10.2 & 10.7 & 93.2 & 19.5 & 92.7 & 25.1 & 89.6 & 17.7 & 85 & 18.7 & 883 \\
EXP04 & 57.1 & 10.5 & 11 & 81 & 19.6 & 93.3 & 24.8 & 85.5 & 17.3 & 84.1 & 18.8 & 817 \\
EXP05 & 63.2 & 10.7 & 11.2 & 82.6 & 20.1 & 93.3 & 26.2 & 86.6 & 18.2 & 89 & 19.3 & 976 \\
EХP06 & 61.9 & 10.7 & 11.2 & 83.8 & 20.1 & 93.7 & 26.1 & 86.4 & 18.2 & 86.7 & 19.3 & 950 \\
\hline
\end{tabular}

water steam was condensed. The difference in $H_{1}$ and $H_{4}$ is given by the different temperature. The amount of condensate grew with increasing temperature and flow rate inside membrane module, because the water inside the module evaporated faster.

\section{Conclusions}

The polymeric distillation could be an alternative to metal desalination units since it does not suffer from exposure to salt water and it is low weight and more environment friendly. This paper presents a prototype based on membrane distillation, which important parts are made from polypropylene. The prototype was operated without any interruption or failure. The experimental verification of prototype showed that the thermal difference between the brine inside the membrane fibres and inside the tunnel is high enough to be a driving force for distillation. The unit began to distil when temperature of the brine was $30^{\circ} \mathrm{C}$, but the volume of condensed water per hour grew with increasing temperature and flow inside the membrane module, therefore it is better to operate the unit at higher temperature.

\section{Acknowledgments}

This work was supported by the Ministry of Education, Youth and Sports of the Czech Republic under OP RDE grant number CZ.02.1.01/0.0/0.0/16_ 019/0000753 "Research centre for low-carbon energy technologies".

\section{References}

Bulejko, P., Dohnal, M., Pospisil, J. and Sverak, T. Air filtration performance of symmetric polypropylene hollow-fibre membranes for nanoparticle removal In: Separation and Purification Technology, 197, pp 122-128.

Darestani, M., Haigh, V., Couperthwaite, S. J., Millare G. J. and Nghiem L. D. (2017) Hollow fibre membrane contactors for annibua recivery: Current status and future developments In: Journal of Environmental Chemical Engineering, 5, pp 1349-1359.

Drioli, E., Ali, A. and Macedonio F. (2015) Membrane distillation: Recent developments and perspectives In: Desalination, 356, pp 56-84.

Chen, X., Su, Y., Reay, D. and Riffat, S. (2016) Recent reaserch developments in polymer heat exchangers - A review In: Renewable and Sustainable Energy Reviews, 60, pp 1367-1386.

Song, S. and Shan H., Liu, J. and Li, B (2018) Heat transfer study of PVDF hollow fiber heat exchanger for desalination process In: Desalination, 446, pp 1-11.

Sørensen, E., Lam, K. F. and Sudhoff, D. (2014) Special Distillation Applications. In:Distillation, pp 367-401.

Zarkadas, D. M. and Sirkar K. K. (2004) Polymeric Hollow Fiber Heat Exchangers: An Alternative for Lower Temperature Applications In: Ind. Eng. Chem. Res, 43, pp 8093-8106. 